\title{
Effects of Long-Term Storage on Radical Scavenging Properties and Phenolic Content of Kombucha from Black Tea
}

\author{
Chiara La Torre $^{1}$, Alessia Fazio ${ }^{1, *}$, Paolino Caputo ${ }^{2}{ }^{(D)}$, Pierluigi Plastina ${ }^{1}\left(\mathbb{D}\right.$, Maria Cristina Caroleo $^{1}$, \\ Roberto Cannataro $^{1}$ (D) and Erika Cione ${ }^{1}$ (D)
}

1 Department of Pharmacy, Health and Nutritional Sciences, Department of Excellence 2018-2022, University of Calabria, Edificio Polifunzionale, 87036 Rende, Italy; latorre.chiara@libero.it (C.L.T.); pierluigi.plastina@unical.it (P.P.); mariacristinacaroleo@virgilio.it (M.C.C.); r.cannataro@gmail.com (R.C.); erika.cione@unical.it (E.C.)

2 Department of Chemistry and Chemical Technologies, University of Calabria, 87036 Rende, Italy; paolino.caputo@unical.it

* Correspondence: a.fazio@unical.it; Tel.: +39-0984-493013

Citation: La Torre, C.; Fazio, A.; Caputo, P.; Plastina, P.; Caroleo, M.C.; Cannataro, R.; Cione, E. Effects of Long-Term Storage on Radical Scavenging Properties and Phenolic Content of Kombucha from Black Tea. Molecules 2021, 26, 5474. https:// doi.org/10.3390/molecules26185474

Academic Editor: Mirella Nardini

Received: 11 August 2021

Accepted: 7 September 2021

Published: 8 September 2021

Publisher's Note: MDPI stays neutral with regard to jurisdictional claims in published maps and institutional affiliations.

Copyright: (c) 2021 by the authors. Licensee MDPI, Basel, Switzerland. This article is an open access article distributed under the terms and conditions of the Creative Commons Attribution (CC BY) license (https:/ / creativecommons.org/licenses/by/ $4.0 /)$.

\begin{abstract}
Kombucha is a fermented beverage. Its consumption has significantly increased during the last decades due to its perceived beneficial effects. For this reason, it has become a highly commercialized drink that is produced industrially. However, kombucha is still also a homemade beverage, and the parameters which, besides its organoleptic characteristics, define the duration of its potential beneficial properties over time, are poorly known. Therefore, this study aimed to determine the effect of 9-month storage at $4{ }^{\circ} \mathrm{C}$ with 30-day sampling on the $\mathrm{pH}$, total phenolic, and flavonoid contents, free radical scavenging properties of kombucha fermented from black tea. Our results highlighted that, after four months, the phenolic content decreased significantly from the initial value of $234.1 \pm 1.4 \mu \mathrm{g} \mathrm{GAE} \mathrm{mL}^{-1}$ to $202.9 \pm 2.1 \mu \mathrm{g} \mathrm{GAE} \mathrm{mL}^{-1}$, as well its antioxidant capacity tested by two in vitro models, DPPH, and ABTS assays. Concomitantly, the $\mathrm{pH}$ value increased from 2.82 to 3.16. The novel findings of this pilot study revealed that kombucha from sugared black tea can be stored at refrigerator temperature for four months. After this period the antioxidant properties of kombucha are no longer retained.
\end{abstract}

Keywords: kombucha; black tea; long-term storage; antioxidant scavenging activity; total phenolic content

\section{Introduction}

"Kombucha" is the name of a drink obtained by fermenting tea, mainly black or green, with the addition of sucrose, that acts as a substrate for fermentation, and a symbiotic culture of yeast and bacteria, known as "SCOBY" (Symbiotic Cultures of Bacteria and Yeast). The taste of this drink is slightly acidic and slightly carbonated, which makes it popular and pleasing to consumers [1]. Kombucha was first used in East Asia for its beneficial and curative effects only based on anecdotal evidences, since the Tsin dynasty began consuming it in Manchuria. It spread from China to Russia after World War I and then throughout Europe [1].

The fermentation is due to a symbiotic culture of acetic bacteria of the genus Acetobacter and Gluconobacter and different osmophilic yeast species, including genera such as Saccharomycode, Schizosaccharomyces, Zygosaccharomyces, Brettanomyces/Dekkera, Candida, Torulospora, Koleckera, and Pichia e Mycoderma. After fermentation, the kombucha tea is filtered through a cheesecloth and is consumed as a healthy drink. It can also be bottled for commercialization [2].

Almost forgotten for decades, kombucha became very popular again in the early 2000s, thanks to its sudden spread in Australia and in the United States. During the last decades, kombucha transitioned from a homemade fermented beverage to a soft drink produced on 
a large scale for commercial use [2,3]. Chemical analysis of kombucha beverage highlighted the presence of a variety of compounds, such as organic acids, mainly acetic, gluconic, and glucuronic acid, sugars (sucrose, glucose, and fructose), water-soluble vitamins (B1, B2, B6, B12, C), lipids, amino acids, biogenic amines, proteins, ethanol, minerals (manganese, iron, nickel, copper, zinc, plumb, cobalt, chromium, and cadmium), anions (fluoride, chloride, bromide, iodide, nitrate, phosphate, and sulphate), D-saccharic acid-1,4-lactone (DSL), carbon dioxide, and polyphenols [2,3]. Kombucha beverage is a source of bioactive components, such as glucuronic acid and polyphenols displaying antioxidant activity [4-6] The low $\mathrm{pH}$ value of this beverage, especially owing to the presence of acetic acid in particular and a range of other organic acids, makes kombucha a drink with remarkable antimicrobial activity against a broad range of microorganisms [7-10] having also probiotic and symbiotic properties [11].

Many claimed beneficial effects of kombucha may be associated with its antioxidant activities, but when kombucha tea is stored at ordinary temperatures, the biofilm due to the presence of microorganisms continues to form, and might also affect the antioxidant activity. Epigallocatechin-3-gallate (EGCG) and epicatechin-3-gallate are converted into the corresponding epigallocatechin (EGC) and epicatechin (EC), the phenolic concentration in kombucha tea shows a linear increase during the fermentation time [11]. It is worth to note that the beneficial outcomes of the kombucha drink are mainly attributed to the activity of polyphenols, which in turn can act epigenetically $[12,13]$.

Jayabalan et al. studied the effect of temperature $\left(50-90^{\circ} \mathrm{C}\right)$ on biochemical components and free radical scavenging properties of kombucha tea during a storage period of three months [14], concluding that heat treatment was not a suitable method for kombucha tea preservation. Therefore, it is of interest to elucidate the relationship between storage time and the changes of the antioxidant ability of kombucha. In fact, time, temperature, and light can significantly impact the quality and the biological activities of this beverage. To the best of our knowledge, no studies were carried out to determine the effects of storage times for more than three months and at low temperature. Therefore, this study aimed to evaluate the effects of the long-term storage at $4{ }^{\circ} \mathrm{C}$ on the $\mathrm{pH}$, total phenolic and flavonoid contents, and free radical scavenging properties of kombucha during nine months with a sampling of 30 days, in order to evaluate the period during which these parameters are stable.

\section{Results}

\subsection{Monitoring of the $p H$ Values of Kombucha during the Stogare Period}

The $\mathrm{pH}$ values of black tea alone, as well as kombucha tea after one month of fermentation and all the samples over the storage are shown in Figure 1. It was observed that the $\mathrm{pH}$ value of sweetened black tea was 5.59, and it dropped to 2.82 in the kombucha beverage obtained after 30 days of fermentation (white bar) decreasing by about 2.77 units. This latter $\mathrm{pH}$ was used as the control for all the kombucha samples analyzed during nine months of storage. The value remained constant (2.84), till two months by decreasing significantly compared with the control $(* * * p<0.0001)$ of about 0.2 units from months four to six. Then, the $\mathrm{pH}$ value of sample significantly increased up to 3.24 , and it remained constant at these values at less than 0.05 units for the last three months (from months seven to nine).

\subsection{Total Phenolic Content (TPC)}

The total phenolic content (TPC) in all kombucha samples is shown in Figure 2. The results were expressed as $\mu$ g equivalents of gallic acid ( $\mu$ g GAE) per $\mathrm{mL}$ of sample.

The results highlighted that the kombucha obtained after one month of fermentation, used as reference, showed the maximum TPC level which was 1.7 times higher $\left(234.1 \pm 1.4 \mu \mathrm{g} \mathrm{GAE} \mathrm{mL}^{-1}\right)$ than the value of black tea, $\left(137.5 \pm 10.7 \mu \mathrm{g} \mathrm{GAE} \mathrm{mL}^{-1}\right)$, respectively. In the following months (from months two to four), the TPC slowly decreased from $234.1 \pm 1.4$ to $223.5 \pm 0.7 \mu \mathrm{g} \mathrm{GAE} \mathrm{mL}{ }^{-1}$ without significant statistic difference. On 
the contrary, it was decreasing in a time dependent manner, from months five to nine, significantly by about $13 \%\left(202.9 \pm 2.1 \mu \mathrm{g} \mathrm{GAE} \mathrm{mL}{ }^{-1}, * * * * * 0.0001\right)$ at month five, and $34 \%$ at month nine $\left(80.8 \pm 5.4 \mu \mathrm{g} \mathrm{GAE} \mathrm{mL}^{-1}\right)$.

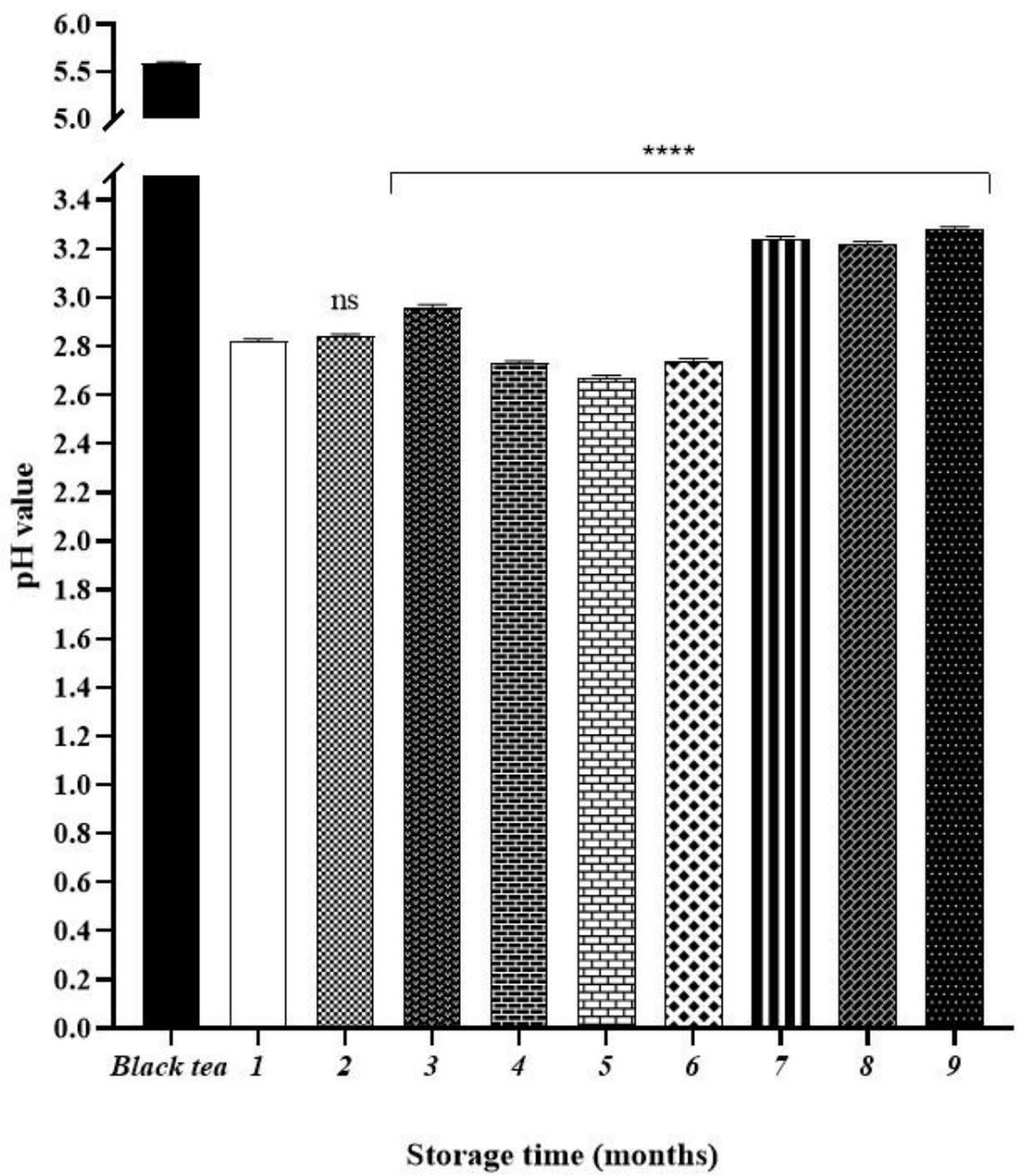

Figure 1. Values of $\mathrm{pH}$ determinate in black tea, kombucha tea after 30 days of fermentation and all the samples during storage. Black bar refers to the starting tea. White bar refers to the kombucha sample after 30 days of fermentation (control). Values represent the three-measure mean \pm standard deviation. Asterisks on the bars indicate that mean values were statistically different from the control $\left({ }^{* * * *} p<0.0001\right)$.

\subsection{HPLC-DAD Analyses}

Five compounds were identified and quantified by HPLC analyses in all samples (Figure 3). Chromatographic evolution at $280 \mathrm{~nm}$ is show in Figure 4A-D.

Caffeine was the main compound in all tea samples. Its initial value in black tea was $568.61 \pm 0.84 \mu \mathrm{g} \mathrm{mL}^{-1}$ (Table 1), which underwent a reduction of $37.34 \%$ after fermentation, of $40.29 \%$ after one month and of $45.37 \%$ after two months. The minimum value was reached after four months $\left(135.36 \pm 1.63 \mu \mathrm{g} \mathrm{mL}^{-1}\right)$ which corresponded to a reduction of the initial value of $76.19 \%$. After six months the caffeine content increased $\left(674.98 \pm 0.49 \mu \mathrm{g} \mathrm{mL}^{-1}\right)$, reaching its maximum value $\left(702.93 \pm 0.02 \mu \mathrm{g} \mathrm{mL}^{-1}\right)$ after nine months. Chlorogenic acid was the only compound that maintained its content unchanged during fermentation and over time compared to the initial value in black tea $\left(29.60 \pm 0.01 \mu \mathrm{g} \mathrm{mL}^{-1}\right)$. EGCG content in tea was $20.58 \pm 0.32$ and remained unchanged after 30 days of fermentation and in the next three months of storage, becoming undetectable at by the fourth month. A similar trend was displayed by ferulic acid, present in a 
smaller amount in black tea $\left(3.15 \pm 0.03 \mu \mathrm{g} \mathrm{mL}^{-1}\right)$. Its content gradually decreased during fermentation in the next five months of storage, becoming undetectable at the sixth month. On the other hand, quercetin, absent in black tea, was identifiable only in the samples after four months from fermentation $\left(23.07 \pm 0.01 \mu \mathrm{g} \mathrm{mL}^{-1}\right)$. Its content remained constant from months five to nine. The results are shown in Table 1.

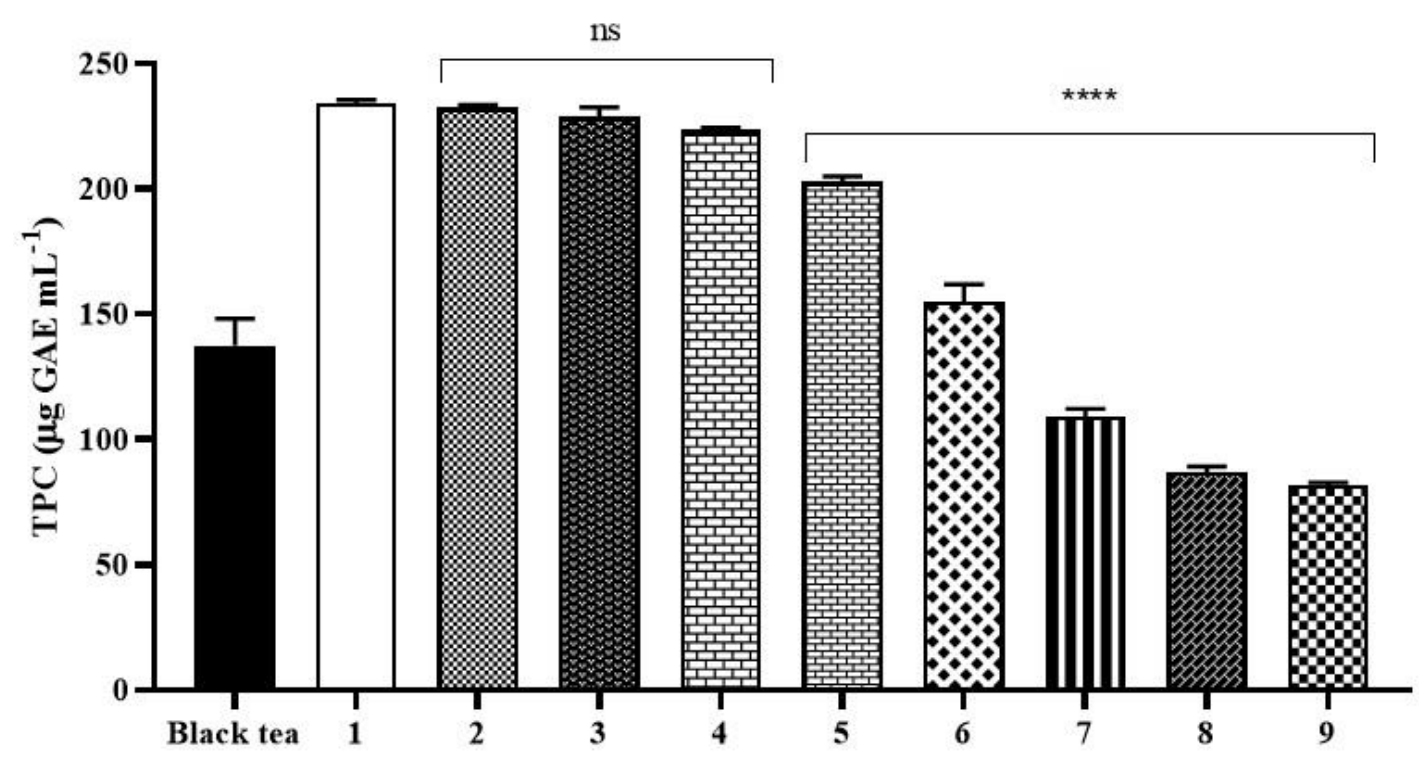

Storage time (months)

Figure 2. Total phenolic content (TPC) ( $\mu \mathrm{g} \mathrm{GAE} \mathrm{mL}^{-1}$ ) of black tea, kombucha tea after 30 days of fermentation and all the samples during storage. Black bar refers to the starting tea. White bar refers to the kombucha sample after 30 days of fermentation (control). Values represent the three-measure mean \pm standard deviation. Asterisks on the bars indicate that mean values were statistically different from the white bar that represents the control $(* * * *<0.0001)$.

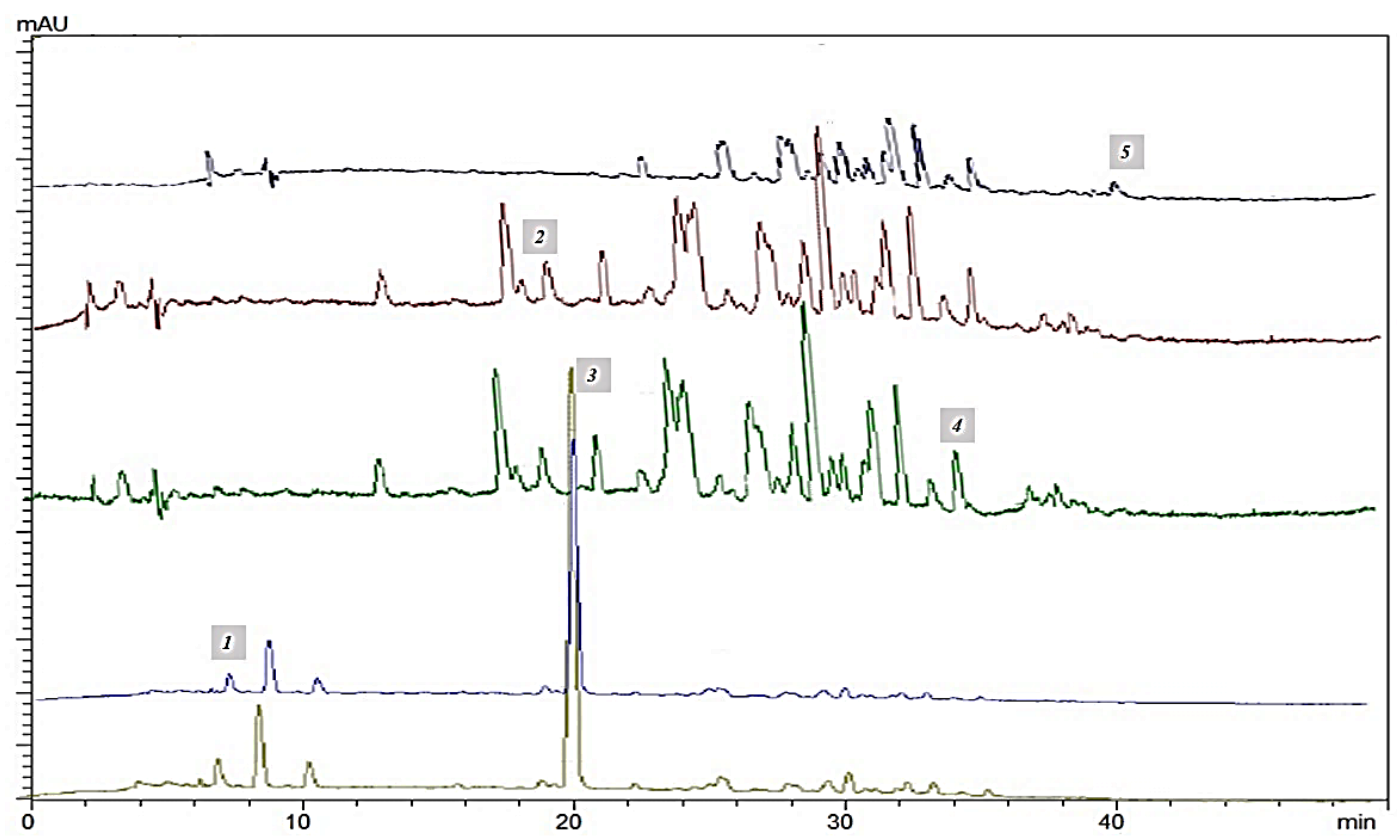

Figure 3. HPLC chromatogram of identified compounds in all the samples at the relative wavelengths to which they have been detected and quantified: 1 . EGCG $(\lambda=280 \mathrm{~nm}) ; 2$. Chlorogenic acid $(\lambda=327 \mathrm{~nm}) ; 3$. Caffeine $(\lambda=273 \mathrm{~nm}) ; 4$. Ferulic acid $(\lambda=325 \mathrm{~nm}) ; 5$. Quercetin $(\lambda=365 \mathrm{~nm})$. 


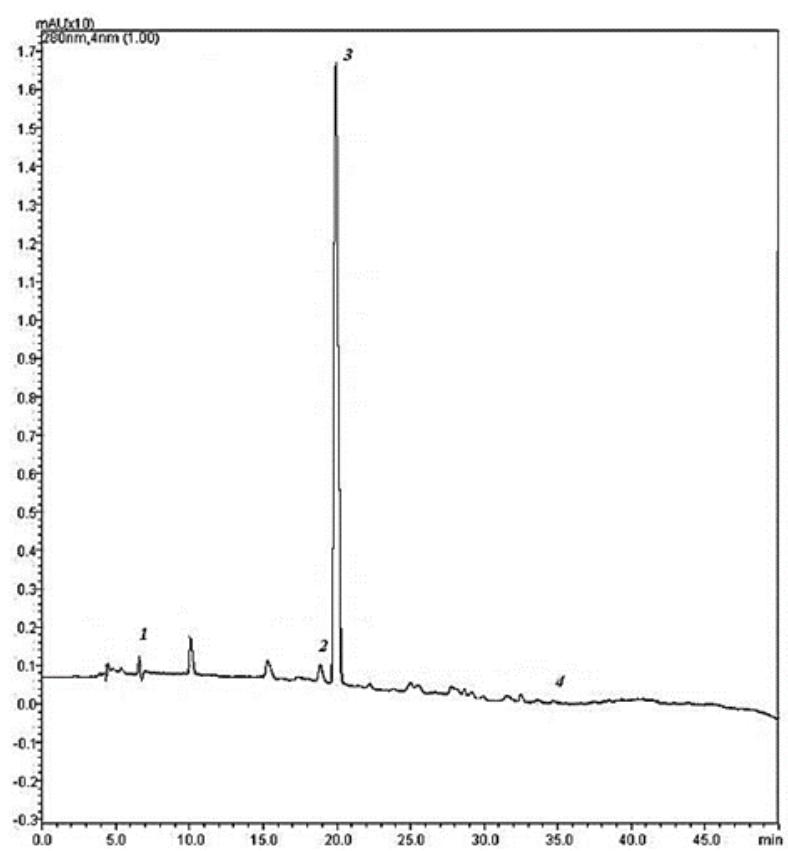

A

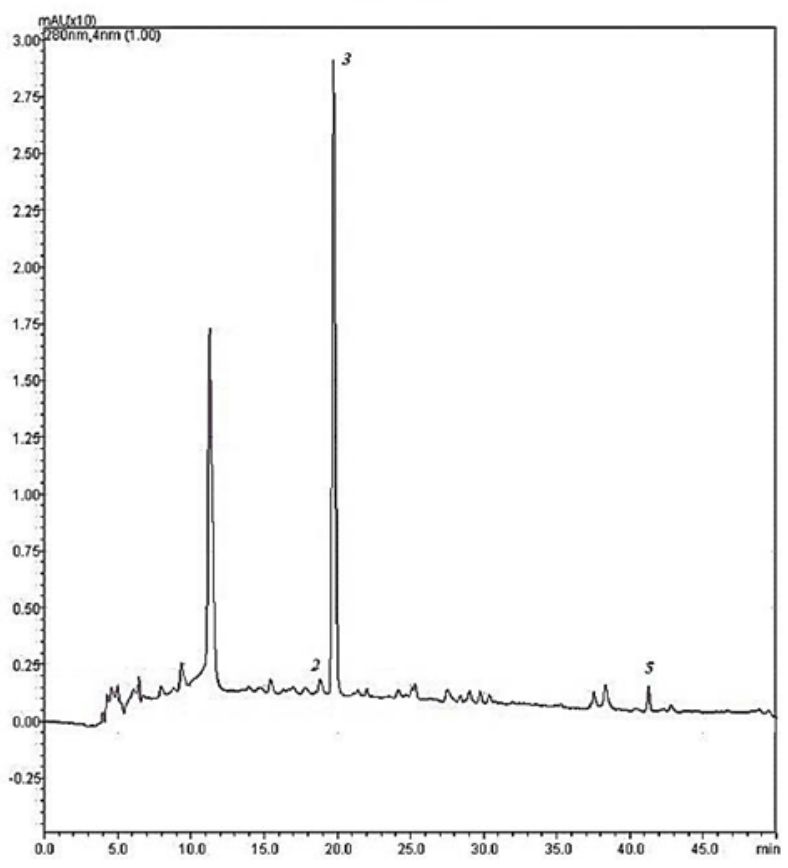

C

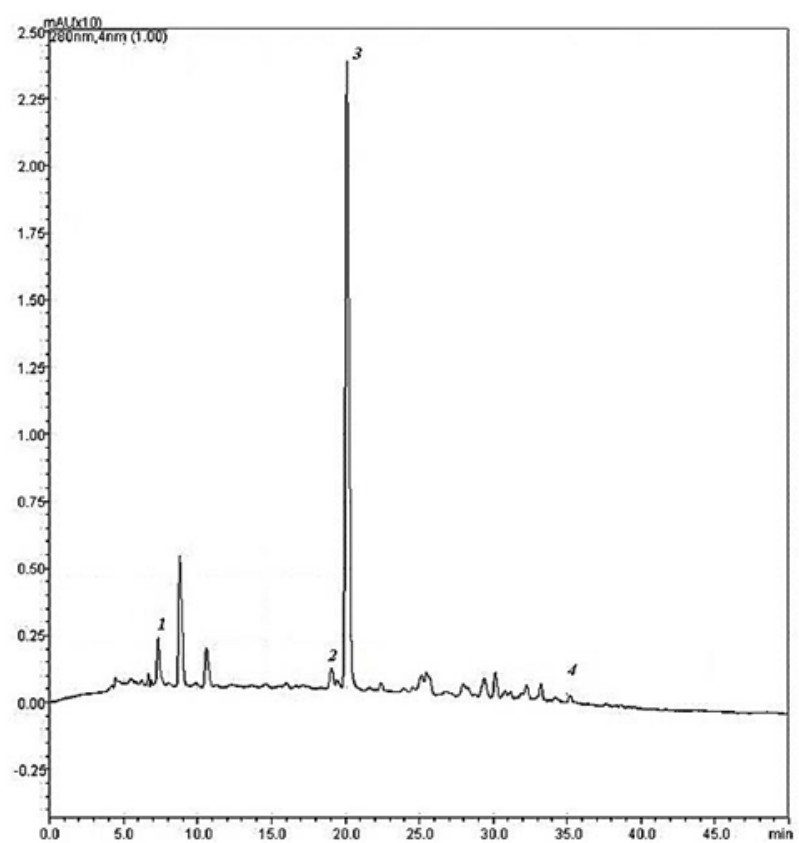

B

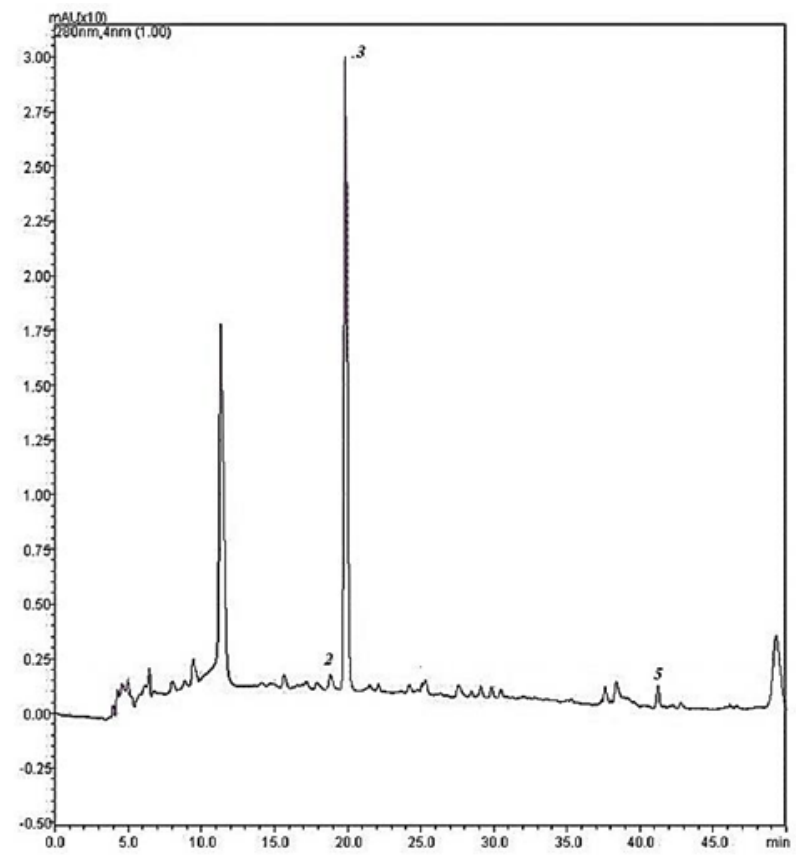

D

Figure 4. Chromatographic evolution at $280 \mathrm{~nm}$ including: (A) black tea; (B) kombucha after one month of fermentation; (C) kombucha tea sample at the fifth month of storage, when the epigallocatechin gallate content was not detected whereas quercetin, absent in black tea, was identifiable; (D) kombucha tea sample at the ninth month of storage.

\subsection{Total Flavonoid Content (TFC)}

Total flavonoid content (TFC) underwent a decrease during fermentation (Figure 5). The initial value of TFC in black tea $\left(2.3 \pm 0.2 \mathrm{QE} \mathrm{mL}^{-1}\right)$ was reduced by $50 \%$ in kombucha tea $\left(1.1 \pm 0.3 \mu \mathrm{g} \mathrm{QE} \mathrm{mL}{ }^{-1}\right)$ and it remained constant over time. 
Table 1. Content of HPLC identified compounds, expressed as $\mu \mathrm{g} \mathrm{mL}{ }^{-1}$.

\begin{tabular}{|c|c|c|c|c|c|}
\hline Samples & Caffeine & Chlorogenic Acid & EGCG & Ferulic Acid & Quercetin \\
\hline Black tea & $568.61 \pm 0.84$ & $29.70 \pm 0.01$ & $20.58 \pm 0.32$ & $3.15 \pm 0.03$ & $\mathrm{nd}^{\mathrm{a}}$ \\
\hline Fermented Kombucha & $356.25 \pm 7.17$ & $29.60 \pm 0.03$ & $20.24 \pm 0.53$ & $2.97 \pm 0.90$ & nd \\
\hline 1st storage month & $339.50 \pm 4.15$ & $29.51 \pm 0.06$ & $19.90 \pm 0.12$ & $1.21 \pm 0.01$ & nd \\
\hline 2nd storage month & $310.63 \pm 0.97$ & $29.56 \pm 0.01$ & $19.96 \pm 0.07$ & $1.30 \pm 0.20$ & nd \\
\hline 3rd storage month & $159.20 \pm 0.55$ & $29.24 \pm 0.38$ & $19.92 \pm 0$ & $0.82 \pm 0.36$ & nd \\
\hline 4th storage month & $135.36 \pm 1.63$ & $29.41 \pm 0.41$ & nd & $0.75 \pm 0$ & nd \\
\hline 5th storage month & $162.60 \pm 0.26$ & $29.64 \pm 0.91$ & nd & $0.41 \pm 0.04$ & $23.07 \pm 0.01$ \\
\hline 6th storage month & $674.98 \pm 0.49$ & $29.72 \pm 0.01$ & nd & nd & $23.16 \pm 0.59$ \\
\hline 7th storage month & $672.27 \pm 0.07$ & $29.58 \pm 0.03$ & nd & nd & $23.23 \pm 0.08$ \\
\hline 8th storage month & $702.91 \pm 0.71$ & $29.72 \pm 0.01$ & nd & nd & $23.03 \pm 0.07$ \\
\hline 9th storage month & $702.93 \pm 0.02$ & $29.60 \pm 0.01$ & nd & nd & $23.04 \pm 0.03$ \\
\hline
\end{tabular}

a Not-detected.

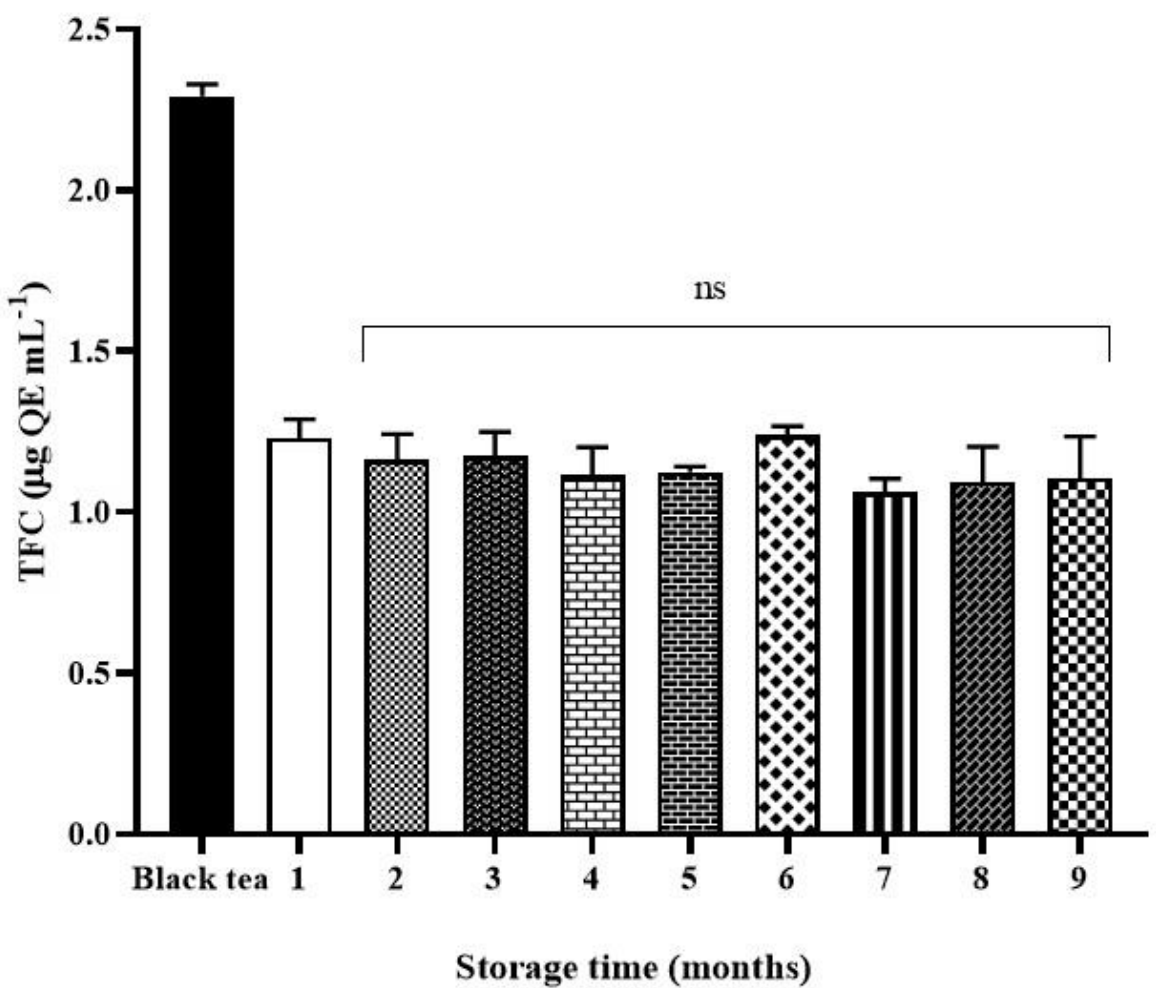

Figure 5. Total flavonoid content (TFC) $\left(\mu \mathrm{g} \mathrm{QE} \mathrm{mL}{ }^{-1}\right)$ of black tea, kombucha tea after 30 days of fermentation and all the samples over storage. Black bar refers to the starting tea. White bar refers to the kombucha sample after 30 days of fermentation (control).

\subsection{Determination of Antioxidant Activity}

Scavenging abilities of black tea, kombucha tea after one month of fermentation and all the samples during the storage were monitored using two common in vitro models, DPPH and ABTS assays.

\subsubsection{DPPH Assay}

Kombucha exhibited good antioxidant activity against DPPH radical during the storage at all tested concentrations when compared to black tea (Figure 6). The results of the DPPH radical assay were also expressed as the Trolox equivalent antioxidant capacity (TEAC) using Trolox as reference standard. The TEAC values are reported in Table 2. During fermentation, $\% \mathrm{I}_{\mathrm{DPPH}}$ of kombucha tea at the highest and lowest concentrations (55.1 \pm 1.3 at $200 \mu \mathrm{L}$, and $10.8 \pm 0.8$ at $10 \mu \mathrm{L}$, respectively) increased by about $70 \%$ compared to that of black tea, which was $16.26 \pm 0.7\left(2.6 \pm 0.1 \mu \mathrm{g} \mathrm{TE} \mathrm{mL}{ }^{-1}\right)$ at $200 \mu \mathrm{L}$, and 
$3.1 \pm 0.1\left(0.8 \pm 0.1 \mu \mathrm{g} \mathrm{TE} \mathrm{mL}^{-1}\right)$ at $10 \mu \mathrm{L}$. At the highest concentration, a $13 \%$ decrease was observed during the first three months of storage with respect to the control value, while it reduced by $30 \%$ after four months. At the fifth month it dropped drastically to a value of $23.2 \pm 6.1 \%\left(3.0 \pm 0.7 \mu \mathrm{g} \mathrm{TE} \mathrm{mL}{ }^{-1}\right)$, corresponding to a reduction of $58 \%$ of the control value $\left.{ }^{* * * *} p<0.0001\right)$. The scavenging ability of kombucha declined to $18.9 \pm 0.4 \%$ $\left(2.9 \pm 0.1 \mu \mathrm{g} \mathrm{TE} \mathrm{mL}{ }^{-1}\right)$ after nine months.

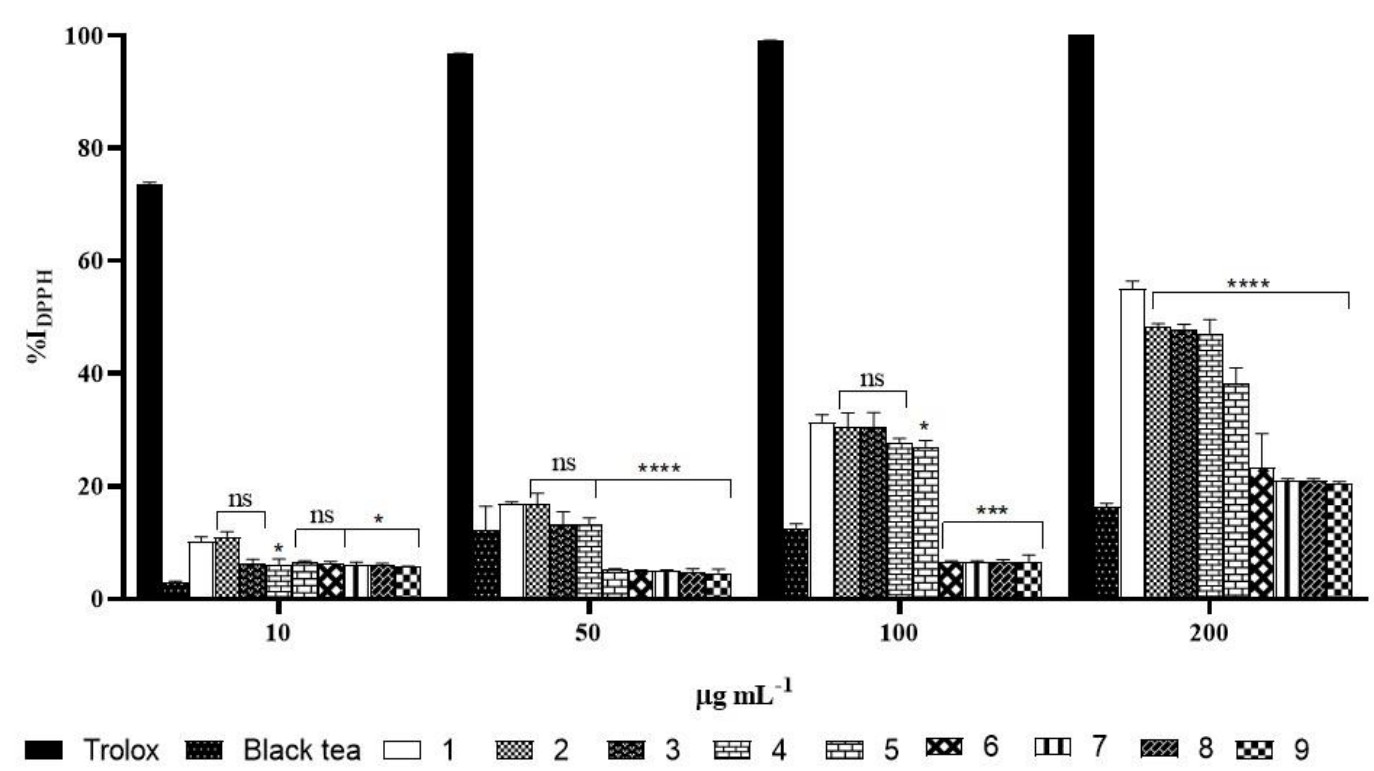

Figure 6. $\% \mathrm{I}_{\mathrm{DPPH}}$ of Trolox, black tea, kombucha tea after 30 days of fermentation and all the samples during storage. White bar refers to \% $\mathrm{I}_{\mathrm{DPPH}}$ of kombucha tea after 30 days of fermentation (control), the others refer to kombucha samples over nine months of storage. Asterisks on the bars indicate that mean values were statistically different from the control $\left({ }^{*} p<0.05,{ }^{* * *} p<0.001,{ }^{* * * *} p<0.0001\right)$.

Table 2. Trolox equivalent antioxidant capacity (TEAC) values ( $\mu \mathrm{g} \mathrm{TE} \mathrm{mL}^{-1}$ ) of different samples against DPPH.

\begin{tabular}{ccccc}
\hline \multirow{2}{*}{ Samples } & \multicolumn{4}{c}{ Concentrations } \\
\cline { 2 - 5 } & $\mathbf{1 0 \mu \mathbf { L }}$ & $\mathbf{5 0 \mu \mathbf { L }}$ & $\mathbf{1 0 0} \boldsymbol{\mu} \mathbf{L}$ & $\mathbf{2 0 0} \boldsymbol{\mu L}$ \\
\hline Black tea & $0.8 \pm 0.1$ & $2.0 \pm 0.6$ & $2.1 \pm 0.1$ & $2.6 \pm 0.1$ \\
Fermented Kombucha & $1.2 \pm 0.1$ & $2.1 \pm 0.1$ & $3.0 \pm 0.2$ & $7.4 \pm 0.2$ \\
1st storage month & $1.3 \pm 0.4$ & $2.1 \pm 0.3$ & $4.3 \pm 0.2$ & $6.3 \pm 0.1$ \\
2nd storage month & $0.7 \pm 0.1$ & $1.5 \pm 0.3$ & $4.0 \pm 0.2$ & $6.4 \pm 0.3$ \\
3rd storage month & $0.6 \pm 1.0$ & $1.7 \pm 0.2$ & $3.6 \pm 0.1$ & $6.3 \pm 0.2$ \\
4th storage month & $0.4 \pm 0.1$ & $0.5 \pm 0.1$ & $3.4 \pm 0.1$ & $5.1 \pm 0.4$ \\
5th storage month & $0.5 \pm 0.1$ & $0.5 \pm 0.1$ & $0.8 \pm 0.1$ & $3.0 \pm 0.7$ \\
6th storage month & $0.6 \pm 0.1$ & $0.7 \pm 0.1$ & $0.8 \pm 0.1$ & $2.8 \pm 0.3$ \\
7th storage month & $0.7 \pm 0.1$ & $1.3 \pm 0.1$ & $2.0 \pm 0.2$ & $2.7 \pm 0.1$ \\
8th storage month & $0.6 \pm 0.1$ & $0.9 \pm 0.1$ & $1.0 \pm 0.6$ & $3.0 \pm 0.3$ \\
9th storage month & $0.6 \pm 0.1$ & $0.9 \pm 0.1$ & $1.2 \pm 0.1$ & $2.9 \pm 0.1$ \\
\hline
\end{tabular}

\subsubsection{ABTS Assay}

The inhibition percentage of ABTS is reported in Figure 7 and the corresponding TEAC values against ABTS are reported in Table 3. Kombucha tea samples showed lower inhibitory abilities on ABTS $\bullet^{+}$radical cation at the highest concentrations (100 and $200 \mu \mathrm{L}$ ) than those against DPPH radical. After one month of fermentation $\% \mathrm{I}_{\mathrm{ABTS}}$ of tea Kombucha at the highest concentrations ( 200 and $100 \mu \mathrm{L}$ ) increased by about $54 \%$ $\left(47.4 \pm 1.3,9.1 \pm 0.3 \mu \mathrm{g} \mathrm{TE} \mathrm{mL}{ }^{-1}\right)$ and $40.6 \%\left(26.6 \pm 0.5,6.1 \pm 0.1 \mu \mathrm{g} \mathrm{TE} \mathrm{mL}{ }^{-1}\right)$ respectively, as compared to the black tea at the same concentrations, that is $21.8 \pm 0.7$ corresponding to 
$4.8 \pm 0.1 \mu \mathrm{g} \mathrm{TE} \mathrm{mL} \mathrm{m}^{-1}$ at $200 \mu \mathrm{L}$ and $15.8 \pm 1.5$ or $3.4 \pm 0.2 \mu \mathrm{g} \mathrm{TE} \mathrm{mL} \mathrm{L}^{-1}$ at $100 \mu \mathrm{L}$. After one month of storage, the abilities of the samples at $200\left(42.3 \pm 0.5,9.1 \pm 0.3 \mu \mathrm{g} \mathrm{TE} \mathrm{mL} \mathrm{mL}^{-1}\right)$ and $100 \mu \mathrm{L}\left(25.0 \pm 0.8,5.5 \pm 0.1 \mu \mathrm{g} \mathrm{TE} \mathrm{mL} \mathrm{L}^{-1}\right)$ were lowered by $11 \%$ and $6 \%$, respectively, compared to the control. The antioxidant capacity of the control at the highest concentration underwent further but progressive reduction up to $27 \%$ in the first three months of storage, but it was reduced by $73 \%\left(\% \mathrm{I}_{\mathrm{ABTS}} 12.7 \pm 0.9\right.$, or $\left.3.4 \pm 0.2 \mu \mathrm{g} \mathrm{TE} \mathrm{mL}{ }^{-1}\right)$ at the fifth month of storage and $85 \%\left(\% \mathrm{I}_{\mathrm{ABTS}} 7.0 \pm 0.4\right.$, or $\left.1.6 \pm 0.1 \mu \mathrm{g} \mathrm{TE} \mathrm{mL}{ }^{-1}\right)$ at the ninth month.



Figure 7. $\% \mathrm{I}_{\mathrm{ABTS}}$ of Trolox, black tea, kombucha tea after 30 days of fermentation and all the samples during storage. White bar (month 1) refers to \% $\mathrm{I}_{\mathrm{ABTS}}$ of kombucha tea after 30 days of fermentation (control), the others refer to kombucha samples over nine months of storage. Asterisks on the bars indicate that mean values were statistically different from the control $\left({ }^{*} p<0.05,{ }^{* * * *} p<0.0001\right)$.

Table 3. Trolox equivalent antioxidant capacity (TEAC) values $\left(\mu \mathrm{g} \mathrm{TE} \mathrm{mL}^{-1}\right)$ of different samples against ABTS.

\begin{tabular}{ccccc}
\hline \multirow{2}{*}{ Samples } & \multicolumn{4}{c}{ Concentrations } \\
\cline { 2 - 5 } & $\mathbf{1 0 \mu \mathbf { L }}$ & $\mathbf{5 0 \mu \mathbf { L }}$ & $\mathbf{1 0 0} \boldsymbol{\mu \mathbf { L }}$ & $\mathbf{2 0 0} \boldsymbol{\mu \mathbf { L }}$ \\
\hline Black tea & $1.8 \pm 0.2$ & $3.0 \pm 0.2$ & $3.4 \pm 0.2$ & $4.8 \pm 0.1$ \\
Fermented Kombucha & $2.8 \pm 0.1$ & $4.5 \pm 0.1$ & $6.1 \pm 0.1$ & $9.6 \pm 0.3$ \\
1st storage month & $2.8 \pm 0.1$ & $4.4 \pm 0.1$ & $5.5 \pm 0.1$ & $9.1 \pm 0.3$ \\
2nd storage month & $2.6 \pm 0.1$ & $3.3 \pm 0.3$ & $5.1 \pm 0.2$ & $7.9 \pm 0.2$ \\
3rd storage month & $1.9 \pm 0.1$ & $2.8 \pm 0.2$ & $4.1 \pm 0.7$ & $7.5 \pm 0.3$ \\
4th storage month & $1.4 \pm 0.2$ & $2.8 \pm 0.1$ & $4.0 \pm 0.5$ & $5.7 \pm 0.1$ \\
5th storage month & $1.2 \pm 0.5$ & $1.6 \pm 0.2$ & $2.3 \pm 0.5$ & $3.4 \pm 0.2$ \\
6th storage month & $0.7 \pm 0.1$ & $1.6 \pm 0.1$ & $1.9 \pm 0.1$ & $3.3 \pm 0.1$ \\
7th storage month & $0.5 \pm 0.1$ & $1.3 \pm 0.1$ & $1.4 \pm 0.1$ & $1.6 \pm 0.1$ \\
8th storage month & $0.4 \pm 0.1$ & $1.1 \pm 0.1$ & $1.3 \pm 0.1$ & $1.5 \pm 0.3$ \\
9th storage month & 0 & 0 & $1.3 \pm 0.2$ & $1.6 \pm 0.1$ \\
\hline
\end{tabular}




\section{Discussion}

The consumption of kombucha has increased over the last decades due to its perceived beneficial effects. For this reason, it has become a highly commercialized drink, industrially produced but is still also a homemade beverage. To evaluate the effects of long-term storage of kombucha on radical scavenging properties and its phenolic content, we kept the tea samples at refrigerator temperature in the dark. Accordingly, to the literature, the $\mathrm{pH}$ values of black tea in the kombucha decreased after 30 days of fermentation due to the metabolic activity of tea fungus yeasts and acetic acid bacteria that produce mainly acetic acid [15].

In fact, the $\mathrm{pH}$ value of sweetened black tea was 5.59, and it dropped to 2.82 in the kombucha beverage obtained after 30 days. Then, the changes in the first five months of storage were less than 0.2 units, while at the sixth month, the $\mathrm{pH}$ value of sample significantly increased up to 3.24 , and it remains constant at these values at less than 0.05 units for the last three months. This $\mathrm{pH}$ rise is most likely due to the subsequent use of acids by bacteria as a carbon source in the absence of sugar in the tea [16,17]. The final $\mathrm{pH}$ of kombucha samples (3.16), after nine months of storage, is still in the safe $\mathrm{pH}$ range of 2.5 to 4.2 for human consumption $[18,19]$.

Total phenolic and flavonoid contents were also monitored after fermentation and during storage. The results highlighted that kombucha after one month of fermentation showed the highest total phenolic content level, which was 1.7 times higher than the value of black tea, as a consequence of the action of microbial enzymes from bacteria and yeasts in an acidic environment, which hydrolyzes complex tea polyphenols into smaller molecular weight phenolic compounds causing an increase in polyphenol concentration [19]. Total phenolic content is reduced after four months of storage. A similar trend was seen for the total flavonoid content but earlier than the total phenolic content.

In contrast to Ning et al. [20], HPLC analysis pointed out that chlorogenic acid maintained its content unchanged either during fermentation and over time compared to the initial value in black tea. On the other hand, all the other monitored phenolics dropped at the fifth month. This agrees with the literature in which the strategy to prolong phenolic content is studied [20]. Conversely, total flavonoid content was constantly lower in black tea, most likely due to the microbial activity of the SCOBY during fermentation.

The results of DPPH inhibition properties of kombucha tea directly depend on the tea constituents and the components produced during fermentation time (30 days). The decrease of antioxidant capacity during storage was most likely related to microbial transformation of the compounds responsible for the maximum scavenging ability into less potential scavenging structures. On the other hands, the inhibition percentage of ABTS assay showed lower inhibitory abilities in respect to ABTS $\bullet^{+}$radical action.

The antioxidant activities of our tested samples likely depend on the composition and the chemical nature of phenolic compounds [21,22]. Then, during the storage, changes in the composition of antioxidant compounds of kombucha tea might result from the formation of certain compounds as in the case of quercetin in our results, thus leading to a lower antioxidant activity [22].

It is important to mention here, that during the COVID-19 pandemic of 2019-2020 the consumption of fermented food, especially beverages, increased in several countries $[17,23,24]$. In particular, the consumption of industrial kefir and kombucha increased [15,25] and the latter was reported, in the magazine Forbes, as the drink of 2020 [26]. Although, as source of bioactive components that could be beneficial for human health, there is no evidence about systematic human trials being done using kombucha tea [27] and some toxicity related to kombucha consumption has been reported so far when kept in a ceramic pot for six months or in lead-glazed earthenware at refrigerator temperature [28,29]. 


\section{Materials and Methods}

\subsection{Standards and Chemicals}

The kombucha starter (Figure 8) was obtained from Kefiralia (Burumart Commerce S.L, Arrasate, Spain) and was maintained in sugared black tea. Dimethylsulphoxide (DMSO), absolute ethanol and methanol, formic acid, and acetonitrile HPLC-grade were purchased from Carlo Erba (Milan, Italy), Folin-Ciocâlteu reagents, sodium carbonate, DPPH, ABTS, potassium persulfate $\left(\mathrm{K}_{2} \mathrm{~S}_{2} \mathrm{O}_{8}\right)$, aluminium chloride $\left(\mathrm{AlCl}_{3}\right)$, potassium acetate, chloroform, and ethyl acetate were purchased from Sigma Aldrich (Milan, Italy).

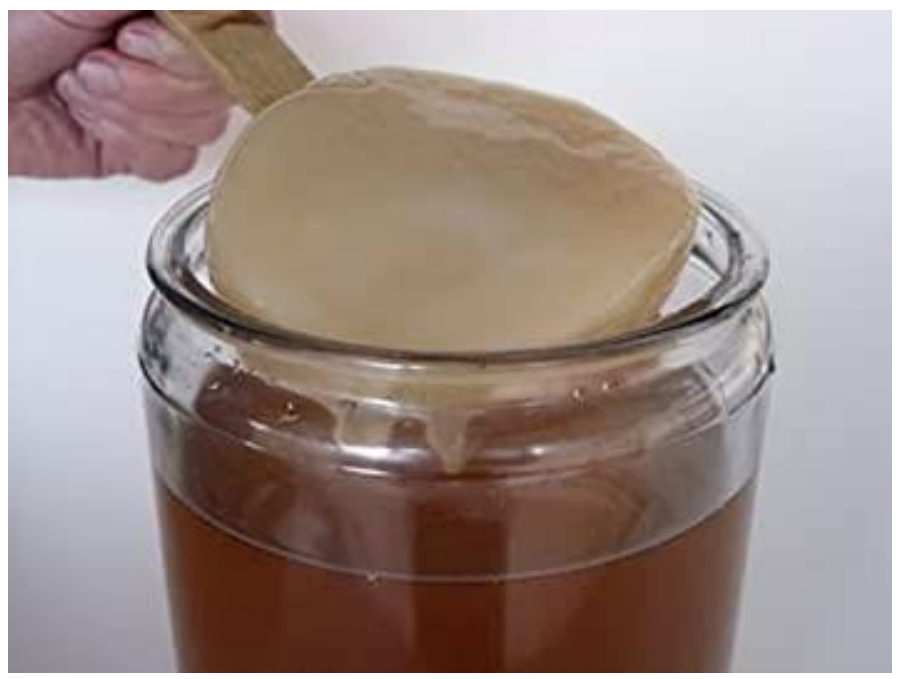

Figure 8. Kombucha starter, the "SCOBY".

\subsection{Preparation of Kombucha Tea and Fermentation Conditions}

Black tea $(3 \mathrm{~g})$ was immersed into $1 \mathrm{~L}$ of boiling water and infused for about $15 \mathrm{~min}$. Then it was filtered through a sterile sieve. This was repeated for three times and $1 \mathrm{~L}$ of each preparation was kept into sterilized glass jars. Commercial sucrose $(7 \%)$ was then added to the hot drink and, after cooling to room temperature, the infusion was inoculated with a commercial kombucha SCOBY $(150 \mathrm{~g})$ size $(15 \times 2 \times 10 \mathrm{~cm})$. The jars were covered with a clean cloth. The fermentation was carried out in the dark at $25 \pm 2{ }^{\circ} \mathrm{C}$ for 30 days and, at the end of this time, the kombucha tea samples were filtered through a cheesecloth and transferred to three amber jars.

\subsection{Storage Condition}

The jars containing kombucha tea were placed in a refrigerator $\left(\mathrm{T}=4{ }^{\circ} \mathrm{C}\right)$ for nine months. Sampling was performed every 30 days by taking an aliquot $(100 \mathrm{~mL})$ which was analyzed. The tea fermented for one month was used as the control for the kombucha tea samples stored at $4{ }^{\circ} \mathrm{C}$ for longer times-up to nine months. $\mathrm{pH}$ values, content of total polyphenol compounds, qualitative and quantitative profile of the main tea polyphenols, content of total flavonoids, and free radical scavenging activities of each sample were determined.

\section{4. $p H$ Values of Tea Kombucha during Storage}

The $\mathrm{pH}$ values of all the kombucha tea samples were measured using an electronic pH meter (Hanna Instruments, George Washington Hwy, Smithfield, RI, USA) calibrated at $\mathrm{pH} 4.0$ and 7.0.

\subsection{Total Phenolic Content (TPC)}

The total polyphenolic content (TPC) compounds in the tea samples were quantified by the Folin-Ciocâlteu colorimetric method as previously described [30], with appropriate 
modifications. The fermented tea sample $(0.1 \mathrm{~mL})$ was transferred in an amber glass vial and was added by $2 \mathrm{~mL}$ of distilled water, $0.5 \mathrm{~mL}$ of the Folin-Ciocâlteu reagent (diluted 1:10 with distilled water), and $0.4 \mathrm{~mL}$ of a $7.5 \%$ sodium carbonate solution $\left(\mathrm{Na}_{2} \mathrm{CO}_{3}\right)$, up to a final volume of $3 \mathrm{~mL}$. The mixture was shaken under constant magnetic stirring for $30 \mathrm{~min}$, at room temperature in the dark. The absorbance was measured at $760 \mathrm{~nm}$ using a spectrophotometer Jasco UV-550. Three analyses were carried out for each sample. Gallic acid was used as the standard in order to plot the calibration curve. For the linearity study, an eight-point calibration curve was constructed using different concentrations of gallic acid stock solutions (range $0.5-0.01 \mathrm{mg} \mathrm{mL}^{-1}$ ). A linear correlation was found between absorbance of the blue complex at $760 \mathrm{~nm}$ and concentration of gallic acid in the range $0.5-0.01 \mathrm{mg} \mathrm{mL}^{-1}(\mathrm{y}=3.6607 \mathrm{x}-0.0036)$. The coefficient $\left(\mathrm{R}^{2}\right)$ obtained from the linear regression was 0.9998 , indicating an excellent linear correlation between the data. The total phenolic content (TPC) was expressed as $\mu$ g equivalents of gallic acid ( $\mu \mathrm{g}$ GAE) per mL of kombucha.

\subsection{HPLC-DAD Analyses}

Five compounds in kombucha tea samples were identified and quantified by reversedphase high performance liquid chromatography coupled with diode array detector (HPLCDAD) [31]. The samples were filtered through a membrane filter $(0.45 \mu \mathrm{m})$ into HPLC vials and analyzed as such. An aliquot $(10 \mu \mathrm{L})$ of each sample was injected into a Shimadzu (Kyoto, Japan) HPLC system equipped with a diode array detector (SPD-M10Avp). The chromatographic separation was performed on a Mediterranea SEA C-18 column $(4.6 \mathrm{~mm}$ i.d. $\times 25 \mathrm{~cm}, 5 \mu \mathrm{m}$ ). The mobile phase was a $0.1 \%$ formic acid (A) and acetonitrile (B) mixture. The gradient used was the following: $0 \mathrm{~min}, 10 \% \mathrm{~B} ; 20 \mathrm{~min}, 22 \% \mathrm{~B} ; 40 \mathrm{~min}, 40 \%$ B; $45 \mathrm{~min}, 10 \% \mathrm{~B}, 51 \mathrm{~min}, 10 \% \mathrm{~B}$. The flow rate and column temperature were maintained as $0.6 \mathrm{~mL} \mathrm{~min}^{-1}$ and at room temperature, respectively. Detection was made at the absorption maxima of the pure standard compounds: caffeine was detected at $273 \mathrm{~nm}$, EGCG at $280 \mathrm{~nm}$, ferulic acid at $325 \mathrm{~nm}$, chlorogenic acid at $327 \mathrm{~nm}$, and quercetin at $365 \mathrm{~nm}$, and identification was made by comparison of the retention times and characteristic UV-Vis spectra of pure standard compounds used as references. Individual components were analyzed quantitatively by the external standard method. The calibration curves for standards (caffeine, EGCG, ferulic acid, chlorogenic acid, and quercetin) were prepared with six appropriate concentrations. The limit of detection (LOD) and the limit of quantification (LOQ) for each standard were calculated as follows: $\mathrm{LOD}=3\left(\mathrm{~S}_{\mathrm{y}} / \mathrm{S}\right)$ and $\mathrm{LOQ}=10\left(\mathrm{~S}_{\mathrm{y}} / \mathrm{S}\right)$, where $S_{y}$ is the standard deviation of the response of the curve and $S$ is the slope of the calibration curve.

\subsection{Total Flavonoid Content (TFC)}

Total flavonoid content (TFC) was determined by a colorimetric method as described previously [32]. Briefly, $0.30 \mathrm{~mL}$ of the sample solution were diluted with $1.68 \mathrm{~mL}$ of distilled water. Then, $0.9 \mathrm{~mL}$ of $\mathrm{MeOH}, 0.06 \mathrm{~mL}$ of a $10 \% \mathrm{AlCl}_{3}$ solution, and $0.06 \mathrm{~mL}$ of $1 \mathrm{M}$ solution of potassium acetate were added to the solution. The mixture was allowed to stand for $30 \mathrm{~min}$ at room temperature, under constant magnetic stirring, in the dark, and then the absorbance was measured against the blank at $420 \mathrm{~nm}$ using a spectrophotometer Jasco UV-550. Three analyses were carried out for each sample. Quercetin was used as the standard in order to plot an eight-point calibration curve. The linearity range of calibration curve was $10-0.001 \mu \mathrm{g} \mathrm{mL}{ }^{-1}(\mathrm{y}=0.084 \mathrm{x}-0.0019)$. The coefficient $\left(\mathrm{R}^{2}\right)$ obtained from the linear regression was 0.9984 , indicating a good linear correlation between the data. The results were expressed as $\mu \mathrm{g}$ of quercetin equivalents ( $\mu \mathrm{g} \mathrm{QE})$ per $\mathrm{mL}$ of kombucha [31].

\subsection{Radical Scavenging Activity}

Two different in vitro assays, DPPH and ABTS, were used to evaluate the changes over time in free-radical scavenging abilities of all kombucha tea samples. 


\subsubsection{DPPH Assay}

The scavenging activity on DPPH radical was determined by the colorimetric method previously described [25] with slight modification. To different volumes of each sample $(10,50,100,200 \mu \mathrm{L}), 0.1 \mathrm{~mL}$ of DPPH solution $(1 \mathrm{mM})$ and $2.8 \mathrm{~mL}$ of $\mathrm{MeOH}$ were added. After an incubation time of $30 \mathrm{~min}$, under magnetic stirring, at room temperature and in the dark, the reduction of DPPH free radical was measured by reading the absorbance at $517 \mathrm{~nm}$ using a spectrophotometer Jasco UV-550. The experiments were carried out against a blank ( $3 \mathrm{~mL}$ of $\mathrm{MeOH})$ and a control (2.9 mL of MeOH, $0.1 \mathrm{~mL}$ DPPH solution). Each sample was tested in triplicate. The antioxidant activity was given as a percentage of free radical inhibition $\left(\% \mathrm{I}_{\mathrm{DPPH}}\right)$, according to the formula:

$\% \mathrm{I}_{\mathrm{DPPH}}=[($ absorbance of the control - absorbance of the sample $) /$ absorbance of the control)] $\times 100$.

The results were expressed also as $\mu \mathrm{g}$ of Trolox equivalents per $\mathrm{mL}$ of tea samples ( $\left.\mu \mathrm{g} \mathrm{TE} \mathrm{mL}^{-1}\right)$.

\subsubsection{ABTS Assay}

ABTS $\bullet^{+}$radical cation is well soluble in both aqueous and organic solvents, so this method can be extensively used to determine antioxidant activity for both hydrophilic and lipophilic compounds [33]. This radical cation was formed by a reaction between $7 \mathrm{mM}$ ABTS solution and $2.45 \mathrm{mM}$ potassium persulfate $\left(\mathrm{K}_{2} \mathrm{~S}_{2} \mathrm{O}_{8}\right)$, and then allowing the mixture to stand for $16 \mathrm{~h}$ in darkness at room temperature. It remains stable for the following $48 \mathrm{~h}$, and is characterized by an intense green/blue color. ABTS $\bullet^{+}$solution was diluted in methanol until the absorbance reached the value of $0.70 \pm 0.02$ at $734 \mathrm{~nm}$. Different volumes of each tea broth sample $(10,50,100,200 \mu \mathrm{L})$ were mixed with ABTS solution $(3 \mathrm{~mL})$, and the absorbance was recorded at $734 \mathrm{~nm}$ after $10 \mathrm{~min}$ of incubation at room temperature in the dark, against a blank and a control. Each sample was tested in triplicate. The radical scavenging activity was given as percentage of ABTS $\bullet^{+}$radical inhibition (\% $\left.\mathrm{I}_{\mathrm{ABTS}}\right)$, according to the following formula:

$\% \mathrm{I}_{\mathrm{ABTS}}=[($ absorbance of the control - absorbance of the sample $) /$ absorbance of the control)] $\times 100$.

The results were expressed as $\mu \mathrm{g}$ of Trolox equivalents per $\mathrm{mL}$ of tea kombucha samples $\left(\mu \mathrm{g} \mathrm{TE} \mathrm{mL}^{-1}\right)$.

\subsection{Statistical Analysis}

Each tea broth from three different preparations, was analyzed in triplicate and, the results were expressed as mean \pm standard deviation (SD). One-way ANOVA method and a Holm-Sidak comparison method via GraphPad Prism 8 were used. The significance was established at $p$ values $<0.05\left(^{*}\right), p<0.01\left(^{* *}\right), p<0.001\left(^{* * *}\right)$, and $p<0.0001\left(^{* * * *}\right)$.

\section{Conclusions}

The polyphenol content of kombucha during long-term storage decreases significantly from the fifth month on and becomes one-third of the initial value after nine months. Therefore, a period of up to four months ensures the preservation of polyphenols of kombucha tea and their antioxidant activities. The results of this pilot study highlighted that the "shelf life" of kombucha stored at refrigerator temperature could be no longer than four months, as only during this period the preservation of polyphenol content and its antioxidant activities are ensured.

Author Contributions: Methodology and writing—original draft preparation, C.L.T.; coordinating the work and writing-review and editing, A.F., E.C.; software, P.C.; validation, P.P., R.C. and M.C.C.; conceptualization and supervision, E.C. All authors have read and agreed to the published version of the manuscript.

Funding: C.L.T. is supported by MIUR (Ministero Istruzione Università e Ricerca) fellow grant for PhD students for Translational Medicine doctorate course at University of Calabria. 
Institutional Review Board Statement: Not applicable.

Informed Consent Statement: Not applicable.

Data Availability Statement: The data presented in this study are available on request from the corresponding author.

Conflicts of Interest: The authors declare no conflict of interest.

Sample Availability: Samples of the compounds are available from the authors.

$\begin{array}{ll}\text { Abbreviations } \\ \text { EtOH } & \text { Ethanol } \\ \text { MeOH } & \text { methanol } \\ \text { DMSO } & \text { dimethylsulfoxide } \\ \text { TPC } & \text { total phenolic content } \\ \text { TFC } & \text { total flavonoid content } \\ \text { DPPH } & \text { 2,2'-diphenyl-1-picrylhydrazyl } \\ \text { ABTS } & \text { 2,2'-azino-bis(3-ethylbenzothiazolin-6-sulfonic) } \\ \text { Trolox } & \text { 6-hydroxy-2,5,7,8-tetramethylcroman-2-carboxylic acid } \\ \text { HPLC } & \text { High Performance Liquid Chromatography } \\ \text { QE } & \text { quercetin equivalents } \\ \text { GAE } & \text { gallic acid equivalents } \\ \text { EGCG } & \text { epigallocatechin-3-gallate } \\ \text { ECG } & \text { epicatechin-3-gallate } \\ \text { EGC } & \text { epigallocatechin } \\ \text { EC } & \text { epicatechin }\end{array}$

\section{References}

1. Watawana, M.I.; Jayawardena, N.; Gunawardhana, C.B.; Waisundara, V.Y. Health, wellness, and safety aspects of the consumption of kombucha. J. Chem. 2015, 2015, 591869. [CrossRef]

2. Jayabalan, R.; Malbaša, R.V.; Lončar, E.S.; Vitas, J.S.; Sathishkumar, M. A review on kombucha tea-Microbiology, composition, fermentation, beneficial effects, toxicity, and tea fungus. Compr. Rev. Food Sci. 2014, 1, 538-550. [CrossRef]

3. Jayabalan, R.; Malini, K.; Sathishkumar, M.; Swaminathan, K.; Yun, S.E. Biochemical characteristics of tea fungus produced during kombucha fermentation. Food Sci. Biotechnol. 2010, 19, 843-847. [CrossRef]

4. Vīna, I.; Linde, R.; Patetko, A.; Semjonovs, P. Glucuronic acid from fermented beverages: Biochemical functions in humans and its role in health protection. Int. J. Recent Res. Appl. Stud. 2013, 14, 17-25.

5. Martínez Leal, J.; Valenzuela Suárez, L.; Jayabalan, R.; Huerta Oros, J.; Escalante-Aburto, A. A review on health benefits of kombucha nutritional compounds and metabolites. CYTA J. Food 2018, 16, 390-399. [CrossRef]

6. Fazio, A.; La Torre, C.; Caroleo, M.C.; Caputo, P.; Cannataro, R.; Plastina, P.; Cione, E. Effect of addition of pectins from jujubes (Ziziphus jujuba Mill.) on vitamin C production during heterolactic fermentation. Molecules 2020, 25, 2706. [CrossRef]

7. Chu, S.C.; Chen, C. Effects of origins and fermentation time on the antioxidant activities of kombucha. Food Chem. 2006, 98, 502-507. [CrossRef]

8. Sreeramulu, G.; Zhu, Y.; Knol, W. Kombucha fermentation and its antimicrobial activity. J. Agric. Food Chem. 2000, 48, 2589-2594. [CrossRef] [PubMed]

9. Sreeramulu, G.; Zhu, Y.; Knol, W. Characterization of antimicrobial activity in Kombucha fermentation. Acta Biotechnol. 2001, 21, 49-56. [CrossRef]

10. Santos Junior, R.J.; Batista, R.A.; Rodrigues, S.A.; Filho, L.X.; Silva Lima, A. Antimicrobial activity of broth fermented with Kombucha colonies. J. Microb. Biochem. Technol. 2009, 1, 72-78. [CrossRef]

11. Kozyrovska, N.O.; Reva, O.M.; Goginyan, V.B.; De Vera, J.P. Kombucha microbiome as a probiotic: A view from the perspective of post-genomics and synthetic ecology. Biopolym. Cell 2012, 28, 103-113. [CrossRef]

12. Cannataro, R.; Fazio, A.; La Torre, C.; Caroleo, M.C.; Cione, E. Polyphenols in the Mediterranean Diet: From Dietary Sources to microRNA Modulation. Antioxidants 2021, 10, 328. [CrossRef] [PubMed]

13. Cione, E.; La Torre, C.; Cannataro, R.; Caroleo, M.C.; Plastina, P.; Gallelli, L. Quercetin, Epigallocatechin Gallate, Curcumin, and Resveratrol: From Dietary Sources to Human MicroRNA Modulation. Molecules 2019, 25, 63. [CrossRef]

14. Jayabalan, R.; Marimuthu, S.; Thangaraj, P.; Sathishkumar, M.; Binupriya, A.R.; Swaminathan, K.; Yun, S.E. Preservation of Kombucha Tea-Effect of Temperature on Tea Components and Free Radical Scavenging Properties. J. Agric. Food Chem. 2008, 56, 9064-9071. [CrossRef] [PubMed] 
15. Plastina, P.; Gabriele, B.; Fazio, A. Characterizing traditional rice varieties grown in temperate region of Italy: Free and Bound phenolic and lipid compounds and in vitro antioxidant properties. Food Qual. Saf. 2018, 2, 89-95. [CrossRef]

16. Sembiring, L.N.; Elya, B.; Sauriasari, R. Phytochemical screening, Total Flavonoid and Total Phenolic content and Antioxidant Activity of Different Parts of Caesalpinia bonduc (L.) Roxb. Pharmacogn. J. 2018, 10, 123-127. [CrossRef]

17. Essawet, N.A.; Cvetković, D.; Velićanski, A.; Canadanović-brunet, J.; vulić, J.; Maksimović, V.; Markov, S. Polyphenols and antioxidant activities of kombucha beverage enriched with coffeeberry extract. Chem. Ind. Chem. Eng. Q 2015, 21, 399-409. [CrossRef]

18. Plastina, P.; Fazio, A.; Gabriele, B. Comparison of fatty acid profile and antioxidant potential of extracts of seven Citrus rootstock seeds. Nat. Prod. Res. 2012, 26, 2182-2187. [CrossRef] [PubMed]

19. Voidarou, C.; Antoniadou, M.; Rozos, G.; Tzora, A.; Skoufos, I.; Varzakas, T.; Lagiou, A.; Bezirtzoglou, E. Fermentative Foods: Microbiology, Biochemistry, Potential Human Health Benefits and Public Health Issues. Foods 2021, 10, 69. [CrossRef]

20. Skocińska, N.; Sionek, B.; Ścibisz, I.; Kołożyn-Krajewska, D. Acid contents and the effect of fermentation condition of Kombucha tea beverages on physicochemical, microbiological and sensory properties. CyTA-J. Food 2017, 15, 601-607. [CrossRef]

21. Cardoso, R.R.; Neto, R.O.; Dos Santos D'Almeida, C.T.; do Nascimento, T.P.; Pressete, C.G.; Azevedo, L.; Stampini Duarte Martino, H.; Cameron, L.C.; Ferreira, M.S.L.; de Barros, F.A.R. Kombuchas from green and black teas have different phenolic profile, which impacts their antioxidant capacities, antibacterial and antiproliferative activities. Food Res. Int. 2020, 128, 108782. [CrossRef]

22. Jakubczyk, K.; Kałduńska, J.; Kochman, J.; Janda, K. Chemical Profile and Antioxidant Activity of the Kombucha Beverage Derived from White, Green, Black and Red Tea. Antioxidants 2020, 9, 447. [CrossRef]

23. Xu, Y.Q.; Chen, J.X.; Du, Q.Z.; Yin, J.F. Improving the quality of fermented black tea juice with oolong tea infusion. J. Food Sci. Technol. 2017, 54, 3908-3916. [CrossRef]

24. Ning, Y.; Wu, Z.; Li, Z.; Meng, R.; Xue, Z.; Wang, X.; Lu, X.; Zhang, X. Optimization of Fermentation Process Enhancing Quality of Dandelion Black Tea on the Functional Components, Activity and Sensory Quality. Open Access Libr. J. 2020, 7, 1-11. [CrossRef]

25. Grumezescu, A.M.; Holban, A.M. The Science of Beverages. In Fermented Beverages, 1st ed.; Woodhead publishing-Elsevier: Sawston, UK, 2019; Volume 5, Chapter 10.

26. Jayabalan, R.; Subathradevi, P.; Marimuthu, S.; Sathishkumar, M.; Swaminathan, K. Changes in free-radical scavenging ability of kombucha tea during fermentation. Food Chem. 2008, 109, 227-234. [CrossRef] [PubMed]

27. Di Renzo, L.; Gualtieri, P.; Pivari, F.; Soldati, L.; Attinà, A.; Cinelli, G.; Leggeri, C.; Caparello, G.; Barrea, L.; Scerbo, F.; et al. Eating habits and lifestyle changes during COVID-19 lockdown: An Italian survey. J. Transl. Med. 2020, 18, 229. [CrossRef] [PubMed]

28. Janssen, M.; Chang, B.P.I.; Hristov, H.; Pravst, I.; Profeta, A.; Millard, J. Changes in Food Consumption during the COVID-19 Pandemic: Analysis of Consumer Survey Data From the First Lockdown Period in Denmark, Germany, and Slovenia. Front Nutr. 2021, 8, 635859. [CrossRef] [PubMed]

29. Ganatsios, V.; Nigam, P.; Plessas, S.; Terpou, A. Kefir as a Functional Beverage Gaining Momentum towards Its Health Promoting Attributes. Beverages 2021, 7, 48. [CrossRef]

30. Available online: https://www.forbes.com/sites/bridgetshirvell/2020/08/13/how-hard-kombucha-became-the-drink-of-2020 (accessed on 6 September 2021).

31. Katarzyna Kapp, J.M.; Sumner, W. Kombucha: A systematic review of the empirical evidence of human health benefit. Ann. Epidemiol. 2019, 30, 66-70. [CrossRef] [PubMed]

32. Srinivasan, R.; Smolinske, S.; Greenbaum, D. Probable gastrointestinal toxicity of Kombucha tea: Is this beverage healthy or harmful? J. Gen. Int. Med. 1997, 12, 643-644. [CrossRef] [PubMed]

33. SungHee Kole, A.; Jones, H.D.; Christensen, R.; Gladstein, J. A case of Kombucha tea toxicity. J. Int. Care Med. 2009, 24, 205-207. [CrossRef] [PubMed] 